\title{
Kodamaea (Pichia) ohmeri: Emerging yeast in diabetic foot and bloodstream infections
}

\author{
Sushma Krishna • Asha Sudheer • Kavitha Dinesh • \\ Harish Kumar • Ajith Kumar Varma • Shamsul Karim
}

Received: 6 August 2013 / Accepted: 13 June 2014 / Published online: 30 December 2014

(C) Research Society for Study of Diabetes in India 2014

Dear Sir,

Diabetes is now a global epidemic and it is expected that India will have the largest number of diabetic patients in the world by 2030 [1]. Diabetic foot infections (DFI) are one of the common complications and fungi, in particular, non-albicans Candida was reported as an increasingly recognized pathogen from our center [2]. The objective now was to assess the clinical significance, associated factors and treatment of K.ohmeri DFI. We reviewed the clinical records during the five year period (Jan 2007-Jan 2012) noting down the demographical details, identifiable risk factors, management and outcome of all the patients in whom $K$. ohmeri was isolated. We processed the deep wound tissue and biopsy samples for culture at $30{ }^{\circ} \mathrm{C}$ on Sabouraud Dextrose Agar, germ tube testing, CHROMagar identification (colonies change color from pink to blue) [3] with final identification and antifungal susceptibility testing by automated API ID $32 \mathrm{C}$ and ATB fungus.

Thirty isolates of Kodamaea ohmeri were reported - tissue (19), blood (6), nail (2) BAL (1), nasal crust (1) and urine (1). Diabetes alone $(P=<0.001)$ and with complications such as neuropathy $(P=<0.001)$, vasculopathy $(P=0.001)$, and nephropathy $(P=0.01)$ were identified together as associated with Kodamaea wound infections $(P=0.001)$. Co-existing bacterial infection was noted in almost all of the tissue samples (18). The MIC values for all the isolates remained uniformly susceptible and no resistant strains were encountered - Amphotericin $(<0.5$ $\mathrm{ug} / \mathrm{ml})$, Fluconazole $(<2 \mathrm{ug} / \mathrm{ml})$, voriconazole $(0.12 \mathrm{ug} / \mathrm{ml})$ and Flucytosine $(1 \mathrm{ug} / \mathrm{ml})$. The patients with blood isolations (6)

S. Krishna $(\bowtie) \cdot$ A. Sudheer $\cdot$ K. Dinesh $\cdot$ S. Karim

Department of Microbiology, Amrita Institute of Medical Sciences, Cochin 682041, Kerala, India

e-mail: sushmakrishna@aims.amrita.edu

H. Kumar • A. K. Varma

Department of Endocrinology, Diabetes \& Podiatric Surgery,

Amrita Institute of Medical Sciences, Cochin 682041, Kerala, India had an indwelling central line and were admitted in different locations. 20 patients received antifungal therapy (19 with fluconazole) of whom, 17 had better outcome of the episode. Three expired with pre-existing illnesses.

The spectrum of fungi causing deep seated wound infections is expanding [4] and Kodamaea ohmeri may be regarded as an emerging pathogen in diabetic foot and blood stream infections. Our report from India highlights the wider spectrum or series of Kodamaea ohmeri infections implicated in DFI for the first time. Fungal cultures must be promptly sought as favorable outcomes are associated with early diagnosis, optimal antifungal regimens, and the removal of indwelling IV catheters. We believe that awareness on the same and reporting of cases across the globe would throw more light on the emerging trend, pathogenesis and therapeutic experience with other antifungals thus establishing optimal regimens for treating $K$. ohmeri infections in the coming future.

Acknowledgments Authors thank Dr. Shashikala Shivaprakasha, exAssociate professor, Microbiology, Amrita Institute of Medical Sciences, Cochin.

\section{References}

1. Wild S, Roglic G, Green A, Sicree R, King H. Global prevalence of diabetes: estimates for the year 2000 and projections for 2030 . Diabetes Care. 2004;27:1047-53.

2. Chellan G, Shashikala S, Sundaram KR, Ajit KV, Narendra V, Mangalanandan TS et al. Spectrum and prevalence of fungi infecting deep tissues of lower limb wounds in patients with type 2 diabetes. Journal of Clin Microbiology 2010; 2097-2012.

3. Fischer F, Cook NB. Fundamentals of diagnostic mycology. 1st ed. Philadelphia: WB Saunders; 1998.

4. Mlinaric Missoni E. M. Vukelic, D. de Soy, M. Belicza, V. Vazic Babic, and E. Missoni. Fungal infection in diabetic foot ulcers. Diabet Med. 2005;22:1124-5. 